lump sum. Had this man been examined before being taken on as a navvy no one would have passed him for such work on account of his deficient physique, and abdominal wall weakness would almost certainly have been noted. In my opinion he should never have been operated on.

I venture to publish this note, hoping it may cause perhaps some surgeons to give consideration to certain elements in these cases, which in the ordinary way do not come within their ken. It is necessarily based on impressions and not on statistics. Ny Hospital Saturday Fund work introduces me to the failures and not to the successes, and possibly causes me to take an unduly pessimistic view of the value of operation for the cure of acquired hernia. At any rate, it will not be wasted if it stimulates any surgeon to make particular inquiry as to how his cases are after an interval of, say, five years after operation.

I am, Sir, yours faithfully,

A. P. GibBons, M.B. Lond.

Finsbury-circus, E.C., Oct. 22nd, 1913.

To the Editor of THE LANCET.

SIR,-Perhaps some of your correspondents would give me their views upon the following question: What period should elapse between the radical operation for inguinal hernia and the resumption of full work-heavy industrialcolliers, steelworkers, \&c.-work? I am in the habit of allowing in cases which have had a normal post-operative course after 17 to 21 days in hospital-two weeks in bedresumption of full work in ten weeks after operation, and after any suppuration-superficial or fascial-a period of 12 to 14 weeks. I do not advise trusses, and I have not had more than some 5 per cent. of recurrences in cases in which one cannot always pick and choose.

I do not think that the periods allowed are too long or that they should be shortened, but there is always pressure on the part of the employers, through medical men, for a much earlier resumption.

Oct. 24th, 1913. I am, Sir, yours faithfully, M.A., M.D., F.R.C.S.

\section{CLAIMS AND CONSULTATIONS.}

\section{To the Editor of THE LANCET.}

Sir, - In the letters last week from Mr. Albert Benthall and from Mr. J. J. Scanlan, I think the ideas of Mr. Benthall in advocating the formation of a small medical board with full powers as to being able to give "final and conclusive decisions" an impossible proposition, as all evidences in the Law Courts go to prove that in contested cases the medical experts are often absolutely at variance.

In Mr. Scanlan's letter, I quite agree that something is wanted to put the safety of the medical fees on the same par as the legal fees. But I would draw his attention to the fact that his well-known position and standing as an expert on "claims" matters give him a position not enjoyed by the ordinary medical practitioner who has to take his fee in the usual medical account, whereas Mr. Scanlan stands in the position of the consultant who obtains his fee usually at the time of consultation, or it is guaranteed to him by the practitioner in charge of the case.

I am, Sir, yours faithfully,

J. M. Clarke, M.B., B.Ch., M.R.C.S.

Regent-street, W., Oct. 20th, 1913.

\section{To the Editor of THE LANCET.}

SIR,-Although I am not a member of the medical profession, may I crave your indulgence to permit me to reply to Mr. J. J. Scanlan's letter in this week's issue of The LANCET?

Having informed us that the "first steps taken by insurance companies upon receiving a claim by an injured party are to have him medically examined," Mr. Scanlan complains that they are asked to pay for the man's own doctor's attendance at such examination. Mr. Scanlan evades any discussion as to the legality of the demand, so we have only to consider the equitable right.

What is the position? The injured man has a medical attendant and is quite satisfied with his advice and treatment, and accordingly enters his claim. His opponents (the insurance company) have to prepare a defence, and with the view of strengthening this they adopt the method of having the injured man medically examined; therefore it is quite clear that this is in their own interest only. 'That being so, why should the man be mulcted in that expenditure?

It is argued that the companies sometimes find that there are very trivial injuries to be seen. Well, if it be true, the companies have learnt that much. Is that any reason why the man should be asked to pay? Insurance companies employ inspectors to investigate claims made on them, and must often find that they are not liable for many such claims; would it be held that as they have obtained that information the claimant should be called upon to pay the cost of the inquiries? It must be agreed that the item is only one of many which fall on the debit side of the "profit and loss" account of the companies' books.

I must not encroach too extensively on your space, although there are many arguments one could submit against Mr. Scanlan's letter.

I am, Sir, yours faithfully,

Gray's Inx-place, W.C., Oct. 27th, 1913. M. WILSON.

\section{ACCIDENTS DUE TO SALVARSAN.}

\section{To the Editor of THE LANCET.}

SIR, - Since the introduction of salvarsan three and a half years have passed. In the meantime a large number of deaths (about 200) and of cases of blindness, deafness, encephalitis hæmorrhagica, paralysis, epileptiform convulsions, and grave poisoning after the employment of salvarsan have been recorded in medical literature. As, in club and private practice, either through fear of publicity or because many colleagues by reason of principle do not publicly record cases, or upon other grounds, many deaths and accidents are not published, I therefore beg my colleagues to inform me of all cases of death, blindness, convulsions, paralysis, \&c., and generally all grave and dangerous incidents occurring after the use of salvarsan, and to add a brief history of the illness, in order that collective statistics may be compiled. For facilitating the sifting of the material received the name of the respective practitioner and place of residence should be given. It is absolutely necessary to collect the concealed cases in order to add them to those cases already reported in literature, and thus be able to form an opinion as to the harmfulness or harmlessness of salvarsan. $\quad$ I am, Sir, yours faithfully,

Potsdamerstrasse 31^, Berlin, Oct. 21st, 1913. Dr. Med. Dreuw.

University of Oxford : Philip Walker StUdentship in Pathology.-The professor of pathology gives notice that an election to this studentship will take place in January, 1914. The studentship was founded for the furtherance of original research in pathology. It is of the annual value of $£ 200$, and is tenable for three years. The student may be of either sex and need not necessarily be a member of the University of Oxford, nor be legally qualified to practise the profession of medicine. While holding the office the time of the student must be wholly devoted to original pathological research; no business or profession may be followed which in the opinion of the professor of pathology and of the board of managers would interfere with the pursuit of original inquiries. The place and the nature of the studies of the student are subject to the approval of the professor of pathology, but the student is bound to pursue these studies within the University during at least three terms of his tenure of his studentship. This requirement may, however, in special circumstances be dispensed with. If the work done by the student be of exceptional promise the studentship may be extended for a second period not exceeding two years. Intending candidates are requested to send letters of application, with three testimonials (one of which should vouch for the candidate's personal character and general education), to the Registrar of the University, University Registry, Oxford, so as to reach him on or before Jan. 7th, 1914 ; ten copies of these papers must be submitted. Copies of the full regulations may be obtained from this source. - The following degrees have been conferred :-D.M., A. D. Waterhouse and G. D. H. Carpenter ; B.M., B.Ch., G. W. Carte. 